
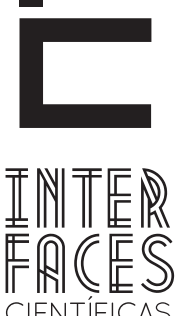

CIENTÍFICAS

HUMANASE SOCIAIS

\title{
AS POSSIBILIDADES JURÍDICAS DA ADOÇÃO EM CONFIGURAÇÃO FAMILIAR HOMOAFETIVA
}

Ariele Faverzani da $\mathrm{Luz}^{1}$

Ariane Faverzani da $\mathrm{Luz}^{3}$
Janaína Faverzani da $\mathrm{Luz}^{2}$

\section{RESUMO}

Este artigo trata da adoção por casais homoafetivos, pautando-se no contexto das novas configurações familiares a fim de aludir possibilidades jurídicas relativas a este contexto. Atualmente, a existência de variados formatos de famílias se revela cada vez mais recorrente, sendo que aquelas compostas por casais de mesmo sexo têm despertado uma maior atenção da sociedade em geral. 0 tema se torna ainda mais complexo quando envolve o desejo deste novo modelo de família em adotar uma criança e/ou adolescente, uma vez que não há norteadores com relação à adoção de casais homoafetivos na Lei 12.010 de 2009, que dispõe sobre a adoção no Brasil. Somam-se a isso, os questionamentos e os discursos, por vezes, resistentes a respeito do assunto em questão. Assim, com a realização deste estudo, foi possível verificar que a resistência em acolher a adoção por casais homoafetivos decorre, principalmente, de falsas ideias que já foram desmistificadas por diversos estudos. Do mesmo modo, constata-se que ainda há muito a ser discutido, visto que, independentemente do gênero do casal adotante, deve-se considerar o bem-estar da criança e do adolescente que busca uma família, pois este se encontra acima de qualquer interesse moral ou social.

\section{PALAVRAS-CHAVE}

Adoção. Homoafetividade. Direito da Criança e do Adolescente. 


\section{ABSTRACT}

This article deals with the adoption by homosexual couples, guiding in the context of the new family configurations in order to allude legal possibilities regarding this context. Currently, the existence of various formats of families are becoming ever more appellant, those composed of same-sex couples have attracted more attention from society in general. The issue becomes even more complex when it involves the desire of this new family model to adopt a child and / or adolescent, since there is no guiding regarding the adoption of homosexual couples in Law 12.010 of 2009, which provides for the adoption in Brazil. Added to this, the questions and speeches sometimes resistant to the subject in question. So with

\section{RESUMEN}

Este artículo aborda la adopción por parejas homosexuales, basándose en el contexto de las nuevas configuraciones familiares para referir las posibilidades legales relacionadas con este contexto. En la actualidad, la existencia de varios formatos de familias revela cada vez más demandante, siendo aquellas compuestas por parejas del mismo sexo han despertado mayor atención de la sociedad en general. El tema se torna aún más complejo cuando se trata del deseo de este nuevo modelo de familia en la adopción de un niño y/o adolescente, ya que no hay ninguna guía con respecto a la adopción de las parejas homosexuales en la Ley 12.010 de 2009, que prevé la adopción en Brasil. Agregado a eso, las preguntas y discursos, a veces duros sobre el tema en cuestión. Así que, con this study, we found that resistance to welcome the adoption by homosexual couples is mainly because of misconceptions that have been demystified by several studies. Similarly, it is clear that much remains to be discussed, since, regardless of the adopter couple genre, one must consider the child's welfare and adolescents seeking a family, as it is above any moral or social interest.

\section{KEYWORDS}

Adoption. Homosexuality. Rights of Children and Adolescents.

realización a este estudio, fue posible comprobar que la resistencia en acogiendo con satisfacción la adopción por parejas homosexuales era debida principalmente a falsas ideas que ya han sido desmitificados por varios estudios. Asimismo, se observa que hay toda vía mucho para ser discutido, ya que, sin importar el género de la patrocinadora de la pareja, debe tener en cuenta el bienestar de los niños y adolescentes que busca una familia, porque está por encima de cualquier interés moral o social.

\section{PALABRAS CLAVE}

Adopción. Homosexualidad. Derecho de los Niños y Adolescentes. 


\section{INTRODUÇ̄̃̃O}

A coexistência de configurações familiares e estruturas familiares diversas têm tornado cada vez mais pertinente a discussão a respeito do conceito "família", nos últimos tempos. Constata-se a dificuldade de traçar um perfil único da família brasileira e, portanto, a necessidade de se falar de famílias no plural e não mais no singular a fim de abarcar a sua complexidade.

Contudo, sabe-se que, independentemente do arranjo familiar, a família é responsável pelas contribuições afetivas, pela construção de um ambiente familiar saudável à criança e ao adolescente e pelo favorecimento de valores éticos e humanitários, uma vez que os(as) filhos(as), integrantes do seio familiar, devem ser protegidos e acolhidos em seu lar conforme preconiza o Estatuto da Criança e do Adolescente (ECA).

Ademais, como nem todas as famílias apresentam uma configuração na qual há uma continuidade biológica, as relações parentais que se formam na família adotiva baseiam-se, de modo geral, em proporcionar um núcleo familiar às crianças e adolescentes que não podem, por algum motivo, ser criadas pelos pais que as geraram. Há, ainda, a possibilidade de ter e criar filhos para pais que possuem limitações genéticas, sejam por questões de infertilidade, sejam por questões de gênero. Em se tratando de adoções que envolvem casais de mesma orientação sexual, nota-se uma resistência social a possibilidade de homoafetivos habilitarem-se para a adoção. 0 discurso que se vê questiona a ausência de referências comportamentais de gênero masculino e feminino e a possível manifestação de sequelas de ordem psicológica.

Neste sentido, o presente artigo busca desmistificar atribuições errôneas baseadas na orientação sexual, bem como, a necessidade de intervenção do Estado no instante em que garante a imputáveis o direito a proteção e ao desenvolvimento integral de modo satisfatório. Ainda, soma-se a discussão a legislação brasileira com relação à adoção e o melhor interesse da criança e do adolescente, uma vez que, ao tratar do tema adoção, estes ocupam uma posição acima de qualquer outro interesse.

\section{ASPECTOS GERAIS DA ADOÇ̃̃O NO BRASIL: HISTÓRIA E LEGISLAÇ̃̃OO}

O contexto histórico da adoção no Brasil se faz presente desde a época da colonização, revelando-se como um dos institutos mais sólidos dos últimos tempos, sendo que por vezes esteve relacionado com a caridade e a prestação de assistência aos menores que se encontravam em situação de vulnerabilidade.

De acordo com o Direito Romano, a adoção consistia em um ato majestoso em que os adotantes reconhecem o adotado como filho mesmo não o sendo por natureza. Rodrigues (1995, p. 27) corrobora com essa afirmação referindo que:

\footnotetext{
No Direito Romano podemos encontrar o seguinte conceito: "adoptio est actus solemnis quo in loco filii vel nepotis adscicitur qui natura talis non est", ou seja: a adoção é o ato solene pelo qual se admite em lugar de filho quem pela natureza não é.
}

A expressão adoção, conforme Nabinger (2010), origina-se do latim, de adoptio, sendo que na língua portuguesa significa "tomar alguém como filho". Assim, é na adoção que o adotado terá o status de filho, por meio do parentesco civil (diferente do parentesco consanguíneo), sendo que para que este estado ocorra, adotante e adotado buscarão firmar vínculos afetivos semelhantes ao da filiação biológica.

Em relação ao real objetivo da adoção, Granato (2010, p. 29-30) ressalta: 
A adoção como hoje é entendida, não consiste em "ter pena" de uma criança, ou resolver situação de casais em conflito, ou remédio para a esterilidade, ou, ainda, conforto para a solidão.

0 que se pretende com a adoção é atender as reais necessidades da criança, dando-lhe uma família, onde ela se sinta acolhida, protegida, segura e amada.

Adotar não é um ato de solidariedade pérfido, nem mesmo obra para solucionar problemas conjugais ou a cura para a infertilidade. A adoção é um ato de ternura que se constitui por meio da formação familiar e que tem por finalidade satisfazer às necessidades de desenvolvimento de uma criança e de um adolescente, a partir da transferência legal a responsabilidade parental dos pais biológicos para os pais adotivos. A adoção vem para prover a criança e/ou adolescente um lar permanente e uma base social segura que vá de encontro as suas necessidades básicas (LEVINZON, 2004). Da mesma forma, a adoção também satisfaz as necessidades da família adotante, pois a chegada de um(a) filho(a) é carregada de expectativas e de renúncias.

Neste sentido, a adoção trata-se da inclusão de maneira decisiva, adquirindo um vínculo jurídico próprio de filiação conforme a legislação vigente. Emprega-se a adoção comumente em casos de crianças que são filhos de pais falecidos ou que possuam identidade ideológica desconhecida em decorrência de abandono parental e, ainda, aos pais que são impedidos juridicamente de exercerem a função familiar por ensejos de força maior.

0 artigo $227^{4}$ da Constituição Federal da República (CF) de 1988 juntamente com o artigo $19^{5}$ do Estatuto

4. Art. 227. CF - É dever da família, da sociedade e do Estado assegurar à criança, ao adolescente e ao jovem, com absoluta prioridade, o direito à vida, à saúde, à alimentação, à educação, ao lazer, à profissionalização, à cultura, à dignidade, ao respeito, à liberdade e à convivência familiar e comunitária, além de colocá-los a salvo de toda forma de negligência, discriminação, exploração, violência, crueldade e opressão.

$\S 6^{\circ}$ - Os filhos, havidos ou não da relação do casamento, ou por adoção, terão os mesmos direitos e qualificações, proibidas quaisquer designações discriminatórias relativas à filiação.

5. Art. 19. ECA - Toda criança ou adolescente tem direito a ser criado e educado no seio da sua família e, excepcionalmente, em família substituta, assegurada a convivência familiar e comunitária, em ambiente livre da presença de pessoas dependentes de substâncias entorpecentes. da Criança e Adolescente garante a todas as crianças e adolescentes o direito de convivência, de educação e de criação no âmbito familiar. O ECA, instituído em 13 de julho de 1990, é um conjunto de normas reguladoras que tem como objetivo de garantir a proteção de crianças e adolescentes com base na Constituição Federal (CF) de 1988. O ECA divide-se em duas partes: a primeira versa sobre os direitos fundamentais e, a segunda a respeito dos procedimentos de proteção.

De acordo com o ECA, criança é aquela que possui idade de até 12 (doze) anos incompletos. A partir dos 12 (doze) anos de idade até os 18 (dezoito) anos passa a ser considerada adolescente. No que tange a adoção, em seu artigo $42^{6}$ dispõe de requisitos, que consistem na caracterização do perfil do adotante: devem ser homens ou mulheres maiores de 18 anos de idade, com diferença mínima de 16 anos de idade entre o adotante e o adotado; não é exigido nenhum estado civil específico, porém o adotante deve oferecer reais vantagens ao adotado.

O ECA também dispõe de artigos ${ }^{7}$ que discriminam as características de quem pode ser adotado: crianças

6. Art. 42. ECA - Podem adotar os maiores de 18 (dezoito) anos, independentemente do estado civil.

$\S 1^{\circ}$ Não podem adotar os ascendentes e os irmãos do adotando.

§ 20 Para adoção conjunta, é indispensável que os adotantes sejam casados civilmente ou mantenham união estável, comprovada a estabilidade da família. $\S 3^{\circ} 0$ adotante há de ser, pelo menos, dezesseis anos mais velho do que o adotando.

$\S 40$ Os divorciados, os judicialmente separados e os ex-companheiros podem adotar conjuntamente, contanto que acordem sobre a guarda e o regime de visitas e desde que o estágio de convivência tenha sido iniciado na constância do período de convivência e que seja comprovada a existência de vínculos de afinidade e afetividade com aquele não detentor da guarda, que justifiquem a excepcionalidade da concessão.

$\S 50$ Nos casos do $\S 40$ deste artigo, desde que demonstrado efetivo benefício ao adotando, será assegurada a guarda compartilhada.

§ 60 A adoção poderá ser deferida ao adotante que, após inequívoca manifestação de vontade, vier a falecer no curso do procedimento, antes de prolatada a sentença.

7. Art. 40. ECA - 0 adotando deve contar com, no máximo, dezoito anos à data do pedido, salvo se já estiver sob a guarda ou tutela dos adotantes.

Art. 45. ECA - A adoção depende do consentimento dos pais ou do representante legal do adotando.

$\S 1^{\circ}$. 0 consentimento será dispensado em relação à criança ou adolescente cujos pais sejam desconhecidos ou tenham sido destituídos do poder familiar. $\S 2^{\circ}$. Em se tratando de adotando maior de doze anos de idade, será também necessário o seu consentimento. 
ou adolescentes com idade de até 18 anos à data do pedido de adoção; que seus pais já sejam falecidos, desconhecidos ou que estejam desaparecidos; que seus pais sejam destituídos do poder de família ou que garantam junto ao Poder Judiciário a intenção de destinar seu filho para a adoção; e, que o adotado maior de 12 anos de idade, manifeste estar de acordo com sua adoção.

Existe a obrigatoriedade de realizar um cadastro nacional de adoção, pelos interessados em adotar e pelos adotáveis em cada comarca ou foro regional, determinado no artigo $50^{8}$ do ECA. Este cadastramento é uma ferramenta auxiliadora para os juízes que permite conduzir as adoções, corroborando com o artigo $31^{9}$ do ECA, que determina que antes de haver uma adoção internacional deve-se observar se não há interessados em adotar com domicílio no Brasil. Além disso, segundo Granato (2010, p. 83):

A principal finalidade, porém, é possibilitar o encontro de pessoas interessadas em adotar, com crianças e adolescentes que possam ser adotados podendo assim haver a concretização de adoções que não ocorreriam, não fosse a oportunidade aberta pelo cadastro nacional de adoção.

Neste sentido, por meio do cadastro nacional de adoção o encontro de crianças e adolescentes com adotantes é beneficiado, estabelecendo desta forma o enlaço da adoção de forma mais ágil por meio do mapeamento de informações unificadas.

Entretanto, à adoção transparece alguns efeitos jurídicos, ou seja, após adotar uma criança ou adolescente incidirá algumas mudanças significativas na vida tanto do adotado quanto do adotante. Para dar início a tais ensejos de transformações Nabinger (2010) destaca a troca de nome do adotado, visto que o adotado

8. Art. 50 A autoridade judiciária manterá, em cada comarca ou foro regional, um registro de crianças e adolescentes em condições de serem adotados e outro de pessoas interessadas na adoção.

9. Art. 31. A colocação em família substituta estrangeira constitui medida excepcional, somente admissível na modalidade de adoção. levará apelidos da nova família e seu prenome ${ }^{10}$ poderá ser modificado; os direitos patrimoniais do adotado em relação à família adotante, pois passará a ter todo e qualquer direito sucessório como filho em relação aos seus ascendentes, descendentes e colaterais; a irrevogabilidade do ato de adoção após a sentença de adoção ter sido publicada e transitada em julgado.

0 artigo $41^{11}$ do ECA reafirma que a adoção atribui ao adotado a condição de filho com direitos e deveres, destituindo de vínculos com pais e parentes biológicos, salvo impedimentos matrimoniais. Denota-se que os requisitos exigidos pela lei brasileira para a adoção de crianças e adolescentes não possuem tamanha severidade.

Assim sendo, como explicar o exorbitante número de pessoas na fila para adotar? Será que estes aspirantes em adotar crianças e adolescentes não correspondem aos requisitos exigidos pela lei? Ou então, será que são raras as crianças e adolescentes que aguardam para serem adotadas?

Em resposta aos questionamentos, pode-se dizer que a demora nos procedimentos de adoção se deve ao fato de que os próprios adotantes dificultam o fluxo do procedimento, uma vez que possuem preferências com relação ao perfil do adotado. Conforme alude a juíza do Conselho Nacional de Justiça (CNJ), Morgana Richa (2010), os adotantes buscam preferencialmente por crianças do sexo feminino com idade inferior ou igual a 03 (três) anos, de cor branca. Este perfil de preferência dificulta o processo de adoção, pois em razão de distintos aspectos, as características mais procuradas são escassas, acarretando, assim, na demora no processo de adoção. Cria-se então a imagem de que no Brasil o procedimento de adoção é moroso,

10. "A troca de prenome deverá ser avaliada e evitada, preservando a identidade da criança. Haverá um novo registro civil, a partir da sentença judicial, a qual terá como conseqüência a lavratura de nova certidão de nascimento, onde constarão os dados do adotante e do adotado. Incluindo seus avós" (NABINGER, 2010, p. 29).

11. Art. 41. A adoção atribui a condição de filho ao adotado, com os mesmos direitos e deveres, inclusive sucessórios, desligando-o de qualquer vínculo com pais e parentes, salvo os impedimentos matrimoniais. 
pois poucos sabem do "gargalo" existente que envolve o processo de adotar.

Outro aspecto que dificulta a adoção das crianças e/ou adolescentes, fazendo com que não pertençam ao perfil procurado pelos adotantes, é a existência de problemas de saúde, comum a mães biológicas que não realizam os cuidados necessários durante a gestação.

No caso dos pais do adotado optar pela separação ${ }^{12}$, não existem modificações na adoção. 0 que difere é a destituição da relação conjugal, mas o poder de família continua a existir, tanto legalmente quanto ao cumprimento do exercício ${ }^{13}$.

Existe um cuidado minucioso ao destinar uma criança e/ou adolescente para uma família, para que tanto a criança e/ou adolescente adotado quanto o adotante tenham segurança na nova relação que ali surge, tornando-se necessária a realização de uma avaliação psicológica para identificar reações e sentimentos que os torneiam.

Ressalta-se a extrema importância da transparência referente à posição que o psicólogo em avaliação psicológica assume frente ao avaliado, na medida em que desde o início deve estar claro qual é a sua função para todos os envolvidos na avaliação (SHINE, 2005). A existência de dificuldades pode prejudicar tanto o objeto quanto o objetivo da intervenção. Assim, conforme assinala Nabinger (2010, p. 37):

A avaliação psicológica terá, portanto, o objetivo de verificar alguns indicadores que mostrem: o estado emocional da criança, sua capacidade intelectual e afetiva conforme a faixa etária, como ela se encontra

12. Art. 1.631. CC - Durante o casamento e a união estável, compete o poder familiar aos pais; na falta ou impedimento de um deles, o outro o exercerá com exclusividade.

Art. 1.632. CC - A separação judicial, o divórcio e a dissolução da união estável não alteram as relações entre pais e filhos senão quanto ao direito, que aos primeiros cabe, de terem em sua companhia os segundos.

13. Art. 1.579. CC - O divórcio não modificará os direitos e deveres dos pais em relação aos filhos. Parágrafo único. Novo casamento de qualquer dos pais, ou de ambos, não poderá importar restrições aos direitos e deveres previstos neste artigo. frente à separação e perda dos pais biológicos e desejo de pertencer a uma nova família.

Ainda, Nabinger (2010) ressalta que as crianças que possuem a oportunidade de compreender a situação na qual se encontram, por vezes, marcada pelo abandono, maus tratos, abuso sexual, entre outros fatores, perpetrados pelos pais biológicos, obterão sucesso na formação de uma nova família. Contudo, para que este sucesso seja alcançado, inicialmente deve-se trabalhar com a criança o conflito interno presente em razão das fantasias frustradas, que gera o medo frente às novas expectativas de futuro.

Neste sentido, para se chegar à apresentação da nova família à criança existe a construção da aproximação por meio de um trabalho realizado junto à mesma, que abrange dados documentais da futura família, como fotografias e cartas, para que ela possa se apropriar da nova fase de sua vida:

\begin{abstract}
Após a primeira etapa de trabalho que dará conta da história pregressa da criança, será apresentada a sua nova família. Primeiramente através de noticias, cartas e fotos para que ela possa formar uma representação mental acerca de seus futuros pais. Em casos de adoção internacional ainda são necessários alguns elementos a respeito da mudança cultural, idioma, necessários, para minimizar o impacto com a aproximação. (NABINGER, 2010, p. 39).
\end{abstract}

O mesmo deve acontecer com os pais adotivos que acompanham todo este procedimento de encontro e acolhimento do filho desejado.

Com relação à adoção internacional, o estrangeiro interessado em adotar uma criança ou adolescente de nacionalidade brasileira deverá solicitar o pedido junto ao seu país de domicílio e obedecer a critérios quanto à formulação do pedido de habilitação que estão claros em lei. Concluída a etapa de pedido de adoção, cuja duração varia de cada país, será formado um dossiê traduzido e legalizado. Caso a legislação do país de acolhida autorizar, admite-se que os pedidos de habilitação à adoção internacional sejam intermediados por Organismos Acreditados (OA). 
Granato (2010, p. 119) define a adoção internacional, também conhecida como adoção transnacional, como "aquela que ocorre quando o adotante tem seu domicílio em um país e o adotado tem residência habitual em outro". A adoção internacional difere da adoção nacional no instante em que se aplicam os ordenamentos jurídicos de ambos os países envolvidos.

Nabinger (2010, p. 119) questiona: "Que sistema de normas deve incidir sobre a adoção internacional? 0 da lei da nacionalidade ou a do domicilio?". Neste caso prevalece a lei da nacionalidade, quando adotando e adotante tiverem nacionalidades diferentes e a legislação reguladora da adoção for a do adotante, conforme ocorre em países como Alemanha, Portugal, Grécia, Japão, China e Coréia. Na Lei de Introdução ao Código Civil nos termos do artigo $7^{014}$, considera-se a lei do domicílio, observando que a lei do país em que é domiciliada a pessoa terá a tarefa de determinar as regras.

Contudo, o Brasil utiliza de todas as precauções necessárias para que a adoção seja tramitada conforme estabelecido em lei, pensando sempre no bem estar do adotante e do adotado, para que ambos possam conviver em harmonia, assegurando todos os direitos reservados, salvaguardando-os de toda negligência que possa existir, conforme prevê a CF de 1988 em seu artigo $227^{15}$.

A adoção no Brasil é regulamentada pela Lei Nacional de número 12.010 de 2009, compatível com o Estatuto da Criança e do Adolescente. A Lei 12.010/09 encara a adoção como medida excepcional e valoriza o que denomina de "família natural",

14. Art. $7^{\circ}$ - LPC - A lei do país em que domiciliada a pessoa determina as regras sobre o começo e o fim da personalidade, o nome, a capacidade es direitos de família.

15. Art. 227. CF - É dever da família, da sociedade e do Estado assegurar à criança, ao adolescente e ao jovem, com absoluta prioridade, o direito à vida, à saúde, à alimentação, à educação, ao lazer, à profissionalização, à cultura, à dignidade, ao respeito, à liberdade e à convivência familiar e comunitária, além de colocá-los a salvo de toda forma de negligência, discriminação, exploração, violência, crueldade e opressão. desmerecendo a existência de arranjos familiares diversos. Acaba, assim, por demonstrar a necessidade de reformulação, pois se revela como uma lei restritiva e limitante de adoção, uma vez que se encontra distante das transformações sucedidas na sociedade contemporânea.

\section{A FAMILLA HOMOAFEITVA E 0 DIREITO A ADOÇÃO}

As transformações ocorridas no núcleo familiar ao longo dos anos vêm ampliando o conceito de família. No entanto, os novos arranjos familiares não devem ser compreendidos como decorrentes de uma crise na instituição familiar, mas como um reflexo das mudanças na sociedade. Giddens (1993) afirma que essas transformações contribuíram para o surgimento de novas formas de relacionamentos, conjugalidade e parentalidade. Assim, há uma reinvenção das características que envolvem a concepção clássica de família, baseada na união de um homem e uma mulher para fins de procriação.

Desde as constituições anteriores a de 1988, a família era apresentada como aquela constituída por homem e mulher originária do casamento, porém, esta descrição se modificou a partir da institucionalização da Constituição Federal da República de 1988. Esta, por sua vez, passou a reconhecer a união estável e a família monoparental ${ }^{16}$ a fim de acompanhar as mudanças ocorridas na vida íntima da sociedade. Desta forma, garantiu-se a possibilidade de todos os brasileiros constituírem uma família sem a necessidade de consumar o casamento, considerando, assim, o ato da adoção uma forma de composição familiar.

De tal modo, os casais homossexuais por almejarem construir uma família, estão optando pela adoção de crianças e adolescentes, o que implica em diversas

16. Art. 226. $\S 4^{\circ} \mathrm{CF}$ - Entende-se, também, como entidade familiar a comunidade formada por qualquer dos pais e seus descendentes. 
discussões acerca deste novo modelo familiar, devido à existência de variados fatores intrínsecos, entre os quais se destaca o preconceito, que em muitos casos fundamenta atitudes violentas. Ademais, no ordenamento jurídico não há uma norma específica que regulamente a união homoafetiva e nem mesmo uma regra que exclua ou implique que os homoafetivos não podem adotar uma criança e/ou adolescente.

Alheios às discussões na sociedade com relação à temática, verifica-se a existência de um contingente de crianças e adolescentes a espera de inserção em um núcleo familiar. Neste sentido, deve-se considerar o direito à convivência familiar e comunitária das crianças e adolescentes, visto que enquanto atores sociais possuem o direito ao estabelecimento de vínculos afetivos, demonstrando que os critérios para a seleção do que venha a ser uma família ideal e apta para adotar uma criança se tornam pouco relevantes frente à interferência trazida pela situação de abandono às crianças e adolescentes institucionalizados.

Portanto, admitir a orientação sexual de casais como um obstáculo que impeça à concretização da adoção e consequentemente a constituição de uma família, significa estar propagando o preconceito, que é contrário ao que prega a legislação do país, ou seja, é uma afronta aos princípios constitucionais da igualdade e da dignidade da pessoa humana. Ainda, o ECA norteia que, no processo de adoção, deve-se considerar como prioridade as reais vantagens para o adotando, revelando, assim a adoção por homoafetivos como uma via real de inclusão e respeito aos direitos da criança e do adolescente.

Recentemente a quarta turma do Superior Tribunal de Justiça (STJ) proferiu uma decisão ${ }^{17}$ referente ao direito de família. Por unanimidade, os ministros permitiram a adoção de duas crianças por um casal homoafetivo de mulheres, negando o recurso para o Ministério Público do estado do Rio Grande do Sul. O pedido de

17. Recurso Especial número 889.852 - RS - STJ (2006 - 0209137-4). Relator ministro Luis Felipe Salomão adoção foi deferido em ambas às instâncias do judiciário. 0 tribunal do Estado do Rio Grande do Sul, por unanimidade reconheceu o pátrio poder de família constituída por duas pessoas de mesmo sexo podendo exercer a adoção de menor para construção familiar.

A decisão menciona, ainda, que já se sabe que estudos com relação à adoção realizada por casais homoafetivos não influi na orientação sexual do adotado e, portanto, não indica qualquer tipo de inconveniência à vida da criança e/ou adolescente que passar a integrar esta nova configuração familiar. Destaca-se que o abandono, a falta de oportunidade de convivência e pertencimento a uma família, o preconceito e a exclusão são os principais geradores de danos à pessoa, sendo estes muitas vezes irreparáveis. Neste sentido, Figueiredo (2004, p. 83) assevera:

\begin{abstract}
Não se pode generalizar a ponto de afirmar que os homossexuais são incapazes de proporcionar um ambiente familiar saudável. Mesmo porque, muitos deles levam vidas inteiramente ajustadas, sem que sua orientação sexual tenha qualquer influência negativa sobre o adotando, ao contrário do que, eventualmente, pode ser observado em alguns heterossexuais que, mesmo enquadrados na visão normal da maioria, podem influenciar, negativamente, aquele a quem adotou, especificamente em função de sua conduta sexual.
\end{abstract}

Recentemente, a Justiça parece, finalmente, ter tomado consciência de que recusar a chancela judicial não impede que casais homoafetivos constituam família (DIAS, 2005). A decisão do Superior Tribunal Federal em reconhecer a união estável entre pessoas de mesmo gênero proporcionou benefícios à adoção de crianças e adolescentes e suscitou a discussão com relação aos direitos e deveres dos casais heterossexuais. Contudo, apesar de não ser uma lei, a unanimidade da decisão influi positivamente para que os demais tribunais passem a olhar por meio de outra perspectiva contextos relativos à adoção por casais homoafetivos.

Faz-se necessário que o Congresso aprove uma legislação que garanta os direitos civis dos homoafetivos tanto para o casamento quanto para a adoção. Não se 
pode julgar a formação de famílias por pessoas de mesmo sexo, na medida em que a negligência, os maus tratos e as práticas parentais inadequadas podem incidir sob qualquer configuração familiar, e, na comprovação de tais casos, deve haver a intervenção judicial para a retirada dos filhos do ambiente familiar inadequado a fim de resguardá-los e protegê-los até ser encontrada a solução mais acertada a estas problemáticas.

A busca pelo reconhecimento de novos direitos ao qual a sociedade clama esta passando por transformações constantes. Barreiras estão sendo derrubadas e ideologias estão sendo reformuladas. Sabe-se que a inovação e a mudança no início assustam, dão medo, contudo, também trazem mudanças significativas que podem beneficiar a sociedade, uma vez que muitos direitos já foram introduzidos e garantidos, proporcionando a construção de uma sociedade mais justa e igualitária. Assim sendo, anseia-se que o mesmo se suceda aos direitos dos homoafetivos por meio do reconhecimento de sua união e o pátrio poder de constituírem uma família no ordenamento jurídico, podendo optar pelo processo adotivo.

Resta evidenciar que, ainda que não exista respaldo jurídico da adoção pelos casais homoafetivos, os Juízos vêm adotando a regra dos benefícios a que passariam prover as crianças destituídas de prerrogativas, passando, ainda que timidamente, a abandonar a orientação sexual como requisito à escolha dos possíveis pais.

\section{CONSIDERACÕ̃ES FINAIS}

O presente artigo abordou a adoção no Brasil por casais homoafetivos. Constatou-se que a grande resistência em acolher a adoção por homoafetivos decorre da falsa ideia de que são relações promíscuas e que, portanto, não ofereceriam um ambiente saudável para o desenvolvimento de uma criança e/ou adolescente. Alega-se, também, a falta de referências parentais para os (as) filhos(as), uma vez que os adotantes são do mesmo gênero. Contudo, diversos estudos já desmistificaram essas afirmações, negando a presença de sequelas no desenvolvimento de quem foi criado por dois pais ou duas mães.

Neste sentido, ao mencionar a adoção por casais homoafetivos, muito ainda se tem a discutir e haverá de ser, no instante em que se faz preciso uma legislação pertinente que regule este novo arranjo de família, visto que independentemente da criança e/ ou adolescente ser adotado por casais de gêneros opostos ou iguais se deve considerar o bem-estar do adotado em todos os momentos. Ademais, o instituto da adoção é um ato jurídico em que o adotante recebe o adotado como filho(a), porém, ressalta-se que este conceito vai muito além de somente receber alguém como filho(a) próprio, dever-se-á considerá-lo, também, como um ato honorífico de amor.

Sabe-se que as mudanças ocorridas na legislação no decorrer dos anos contribuíram significativamente para que a adoção fosse aceita perante a sociedade com naturalidade. Com o subsídio do Estatuto da Criança e do Adolescente conjuntamente com o Cadastro Nacional, foi possível alcançar uma maior compreensão do procedimento de adoção, contribuindo no controle do número de crianças à espera de uma família e, por conseguinte, tornando o processo mais célere.

A adoção internacional, por ser um processo que envolve tanto a legislação do país do adotante quanto à legislação do país do adotado, demonstra a necessidade de um maior cuidado referente à proteção da criança e do adolescente, por motivos pertinentes no que se alude à adaptação do adotado a nova cultura em que será inserido e a forma de vivência da nova família a que instituiu.

De tal modo, destaca-se a que o instituto da adoção não deve ser visto como uma forma de melhorar a situação de crianças e adolescentes abandonados e que se encontram em vulnerabilidade, mas como um ato de nobreza ao buscar integrá-los em lares que possam contribuir com o desenvolvimento saudável, proporcionando uma vida com dignidade e afetividade familiar. 


\section{REFERÊNCIAS}

BRASIL. Constituição Federal de 1988. Brasília: Senado Federal, Centro Gráfico, 1988.

BRASIL. Câmara dos Deputados. Estatuto da criança e do adolescente. 6.ed. Brasília: Centro de Documentação e Informação, 2008.

DIAS, M. B. 0 direito a um lar. Disponível em: <www. mariaberenicedias.com.br>. Acesso em: 10 dez. 2013.

FIGUEIREDO, L. C. B. Adoção para homossexuais. 4.ed. Curitiba: Juruá, 2004.

GIDDENS, A. A transformação da intimidade: sexualidade, amor e erotismo nas sociedades modernas. São Paulo: UNESP, 1993.

GRANATO, E. F. R. Adoção: doutrina e prática. Curitiba: Juruá, 2010.
LEVINZON, G. K. Adoção: clínica psicanalítica. São Paulo: Casa do Psicólogo, 2004.

NABINGER, S. Adoção: o encontro de duas histórias. Santo Ângelo: Furi, 2010.

RICHA, M. Perfil de preferência dificulta adoção. Disponível em: <http://www.clicrbs.com.br/especial/ sc/portal-social/19,0,2773935,Perfil-de-preferencia-dificulta-adocao.html>. Acesso em: 10 jul. 2014.

RODRIGUES, D. A. V. Dicionário de Brocardos Jurídicos. São Paulo: Ateniense, 1995.

SHINE, S. Avaliação Psicológica e Lei: adoção, vitimização, separação conjugal, dano psíquico e outros temas. São Paulo: Casa do Psicólogo, 2005. 